\title{
Single-fraction Stereotactic Radiosurgery for Atypical Meningiomas (WHO grade II): Treatment Results Based on a 25-year Experience
}

\section{Hirotaka Hasegawa}

Mayo Clinic Rochester: Mayo Clinic Minnesota https://orcid.org/0000-0002-3585-2188

\section{Kunal Vakharia}

Mayo Clinic Rochester: Mayo Clinic Minnesota

Link J Michael

Mayo Clinic Rochester: Mayo Clinic Minnesota

Scott L Stafford

Mayo Clinic Rochester: Mayo Clinic Minnesota

\section{Paul D Brown}

Mayo Clinic Rochester: Mayo Clinic Minnesota

lan F Parney

Mayo Clinic Rochester: Mayo Clinic Minnesota

\section{Terry C Burns}

Mayo Clinic Rochester: Mayo Clinic Minnesota

\section{Elizabeth S Yan}

Mayo Clinic Rochester: Mayo Clinic Minnesota

Anita Mahajan

Mayo Clinic Rochester: Mayo Clinic Minnesota

Nadia N Laack

Mayo Clinic Rochester: Mayo Clinic Minnesota

Bruce E Pollock ( $\sim$ Pollock.Bruce@mayo.edu )

Mayo Clinic Rochester: Mayo Clinic Minnesota https://orcid.org/0000-0002-6148-9079

\section{Research Article}

Keywords: atypical meningioma, gamma knife, grade II meningioma, meningioma, radiotherapy, radiosurgery

Posted Date: September 15th, 2021

DOI: https://doi.org/10.21203/rs.3.rs-880804/v1 
License: (c) (i) This work is licensed under a Creative Commons Attribution 4.0 International License. Read Full License 


\section{Abstract}

\section{Purpose}

To clarify the role of stereotactic radiosurgery (SRS) for atypical meningiomas (AM).

Methods

A retrospective analysis of 68 patients with AM having SRS from 1995 until 2019. Nineteen patients $(28 \%)$ had undergone prior external beam radiation therapy (EBRT) (median dose, $54 \mathrm{~Gy}$ ). The median follow-up period was 52 months.

Results

Eighteen (26\%), 17 (25\%), and 33 (49\%) patients received SRS as an upfront adjuvant ( $\leq 6$ months), early salvage (7-18 months), or late salvage treatment (> 18 months), respectively. The 3-, 5-, and 10-year progression-free survivals (PFSs) were $52 \%, 35 \%$, and $25 \%$, respectively. The $3-, 5-$, and 10 -year diseasespecific survivals (DSSs) were $85 \%, 78 \%$, and $61 \%$, respectively. Adverse radiation events (AREs) were observed in 12 patients (18\%), with increased or new seizures being the most frequent complication $(n=7)$. Prior EBRT was associated with reduced PFS (HR $=5.92, P<0.01)$, reduced DSS $(H R=5.84, P$ $<0.01)$, and an increased risk of $A R E(H R=3.31, P=0.04)$. Timing of SRS was correlated with reduced PFS for patients having early salvage treatment compared to upfront adjuvant $(H R=3.17, P=0.01)$ or late salvage treatment $(H R=4.39, \mathrm{P}<0.01)$.

Conclusion

PFS for patients with residual/recurrent AM remains poor despite SRS. Prior EBRT was associated with worse tumor control, higher tumor-related mortality, and an increased risk of ARE. Further study on the timing of SRS is needed to determine if upfront adjunctive SRS improves tumor control compared to salvage SRS.

\section{Introduction}

Meningiomas are the most common intracranial neoplasm with a prevalence of 70.7 per 100,000 individuals. [1] Over the past two decades, the World Health Organization (WHO) has revised the criteria which has provided a more objective classification system used to define the three grades of meningiomas.[2-4] These changes have resulted in the diagnosis of more atypical meningiomas (AM) (WHO grade II) compared to benign meningiomas (BM) (WHO grade I), with the prevalence of anaplastic/malignant meningioma (MM) (WHO grade III) remaining approximately $1-2 \%$. $[5,6]$ AM often behave aggressively with 5 -year tumor recurrence rates of $15-41 \%$ after gross total resection (GTR) and tumor progression rates of 30-70\% after subtotal resection (STR).[7] External beam radiation therapy (EBRT) is commonly used to reduce the chance of tumor growth after resection for patients with AM, but no consensus has been reached as to whether or not post-operative EBRT is beneficial.[8-14] Stereotactic 
radiosurgery (SRS) is also frequently employed for patients with residual or recurrent AM.[15-20] These studies are typically comprised of a heterogeneous group of patients including both AM and MM, patients with genetic conditions such as neurofibromatosis or meningiomatosis, and radiation-induced tumors.

To better understand the patient and treatment factors associated with tumor control, survival, and complications after single-fraction SRS of AM, we retrospectively reviewed our experience over a 25-year interval (1995-2019) excluding patients with syndromic or radiation-induced tumors.

\section{Methods}

We identified 98 patients having SRS for an AM at our center between 1995 and 2019 from a prospective patient registry. Patients included in this study had non-syndromic, non-radiation induced tumors with a minimum of 6 months of follow-up after SRS. Tumor grading was based on the applicable WHO classification system, with patients treated before 2000 having their pathologic specimens reviewed before inclusion in this study. Eighteen patients were excluded because they did not meet the inclusion criteria: radiation-induced tumor $(n=7)$, neurofibromatosis/meningiomatosis-related tumor $(n=5)$, or follow-up less than 6 months $(n=6)$. Eleven patients were excluded because they had prior SRS at other centers $(n=4)$ or concurrent EBRT and SRS $(n=7)$, an older approach that was abandoned after 1996 due to the high incidence of adverse radiation events (ARE). One patient refused research authorization leaving 68 patients available for analysis.

Baseline patient data characteristics, pre-SRS magnetic resonance imaging (MRI), radiosurgical dosimetry, and follow-up clinical and imaging information were retrospectively collected for each patient. Extent of surgical resection was classified as gross total resection (GTR: Simpson grade I-II) and subtotal resection (STR: Simpson grade III-V) based on surgical note and postoperative imaging whenever possible. This study was approved by the Institutional Review Board (IRB \#21-000215). Informed consent was waived given the retrospective non-invasive nature of this study.

\section{Radiosurgery Technique}

All radiosurgical procedures were frame based, single-fraction SRS performed with the Leksell Gamma Knife ${ }^{\circledR}$ (Elekta Instruments, Norcross, GA). Dose planning was performed by dedicated neurosurgeons and radiation oncologists using Leksell GammaPlan $®$ (Elekta Instruments, Norcross, GA) based on postgadolinium spoiled gradient-recalled acquisition (SPGR) MRI. The prescription isodose volume (PIV) covered all recognizable tumor without adding any margin. No cases of post-surgical tumor cavity SRS in the absence of identifiable tumor were performed.

The prescription isodose line was $50 \%$ in 64 cases (94\%). A median of 9 isocenters (interquartile range [IQR], 5-13) were used to cover a median volume of $8.0 \mathrm{~cm}^{3}$ (IQR, 2.9-12.7). The median tumor margin dose was 16 Gy (IQR, 15-18) and the median maximum radiation dose was 32 Gy (IQR, 30-36). 
Clinical evaluation and MRI were typically performed at 3,6 , and 12 months after SRS, and yearly thereafter. In cases who were followed by their local physicians, the follow-up images were sent to us for independent review. Adverse radiation events (ARE) graded using the Common Terminology Criteria for Adverse Events (CTCAE, version 5.0).

Time from last surgery to SRS was categorized into three groups: upfront adjuvant ( $\leq 6$ months), early salvage (7-18 months), and late salvage (> 18 months) (Bonferroni's corrected P-value [ 0.017$]$ was used as a cutoff).[21] Tumor response within the PIV was defined as unchanged (tumor maximum diameter within $20 \%$ of baseline), decreased (tumor maximum diameter decreased by $20 \%$ ), or increased (tumor maximum diameter increased by $20 \%$ ). New tumor growth within $2 \mathrm{~cm}$ of the prescribed radiation dose was defined as marginal progression, and new tumor growth beyond $2 \mathrm{~cm}$ was defined as distant progression. Progression free survival (PFS) (freedom from any type of tumor growth), disease-specific survival (DSS), and cumulative ARE were calculated using the Kaplan-Meier method. Patient and treatment factors were analyzed using univariate and multivariable Cox proportional hazard modeling. Factors with a P-value of $<0.10$ in univariate analysis were entered into the multivariable model. A Pvalue of $<0.05$ was considered significant. JMP Pro 14.0 (SAS Institute, Carry, NC) was used for statistical analysis.

\section{Results}

\section{Patients}

The characteristics of the 68 patients are summarized in Table 1. Eighteen (26\%), 17 (25\%), and 33 (49\%) patients received SRS as an upfront adjuvant, early salvage, and late salvage treatment, respectively. Prior EBRT was performed in 19 patients (28\%). Most patients $(n=51,75 \%)$ had a single tumor, whereas 17 patients $(25 \%)$ had a multi-focal tumor noted at the time of SRS. The median follow-up period was 52 months (IQR, 28-88 months).

\section{Tumor Control}

Thirty-one patients $(46 \%)$ had tumors that were unchanged $(n=9)$ or decreased $(n=22)$ without intracranial progression at a median of 36 months (IQR, 18-54 months). Twenty-six patients (38\%) had the irradiated tumors decrease in size but had marginal $(n=24,35 \%)$ or distant $(n=2,3 \%)$ progression at a median of 24 months (IQR, 13-44). Eleven patients (16\%) had increased tumor size at a median of 12 months (IQR, 835 months). Overall, 37 patients (54\%) had tumor growth (either in-field or marginal progression).

The 3-, 5-, and 10-year PFS was 52\%, 35\%, and 25\%, respectively (Fig. 1A). Patients having prior EBRT ( $\mathrm{P}<$ $0.01, \mathrm{HR} 5.92,95 \% \mathrm{Cl} 2.67-13.04$ ) and early salvage SRS (vs. upfront adjuvant, $\mathrm{P}=0.01, \mathrm{HR} 3.17,95 \% \mathrm{Cl}$ $1.29-7.80$; vs. late salvage. $\mathrm{P}<0.01, \mathrm{HR} 4.39,95 \% \mathrm{Cl} 1.97-9.78$ ) had worse PFS in multivariable analysis (Table 2). The 3-, 5-, and 10-year PFS was $63 \%, 45 \%$, and $31 \%$, respectively, in patients without prior EBRT, 
and $24 \%, 0 \%$, and $0 \%$, respectively, in patients having prior EBRT (Fig. 1B). When stratified by timing of SRS, the $3-, 5$-, and 10 -year PFS were $52 \%, 44 \%$, and $44 \%$, respectively, after upfront adjuvant SRS ( $\leq 6$ months); $33 \%, 0 \%$, and $0 \%$, respectively after early salvage SRS (7-18 months); and $61 \%, 48 \%$, and $27 \%$, respectively, after late salvage SRS (> 18 months) (upfront adjuvant vs. early salvage, $P=0.03$; upfront adjuvant vs. late salvage, $\mathrm{P}=0.89$; early salvage vs. late salvage, $\mathrm{P}<0.01$ [interpreted with Bonferroni's corrected P-value]) (Fig. 1C).

\section{Disease Specific Survival}

Additional tumor directed interventions were performed in 28 patients (41\%) after the initial SRS; 19 patients $(28 \%)$ underwent multiple interventions. By modality, 23 patients $(34 \%)$ had 1 or more SRS procedures with $22(32 \%)$ procedures as the first intervention for recurrence. Repeat surgery was performed in 10 patients (15\%) patients, either as the first intervention for recurrence $(n=5)$ or salvage after 1 or more SRS procedures $(n=5)$. Six patients ( $9 \%)$ patients received EBRT, none of which was performed as the first intervention for recurrence but salvage following surgery $(n=4)$, SRS $(n=1)$, or both $(n=1)$. Bevacizumab was given to 3 patients $(4 \%)$; for first recurrence after initial SRS $(n=1)$, recurrence after combination of repeat SRS and surgery $(n=1)$, and recurrence after combination of surgery and EBRT $(n=1)$.

Over the observation period, 17 patients (25\%) died of causes associated with tumor progression at a median of 36 months (IQR, 19-72 months) after SRS. The 3-, 5-, and 10-year DSS was $85 \%, 78 \%$, and $61 \%$, respectively (Fig. 2A). Univariate analysis showed that patients with multiple tumors $(P=0.04, H R$ 2.65, 95\% $\mathrm{Cl} 1.02-7.15)$ (Fig. 2B) and patients having prior EBRT ( $\mathrm{P}<0.01, \mathrm{HR} 6.15,95 \% \mathrm{Cl} 2.09-18.07$ )

(Fig. 2C) had worse DSS, but only prior EBRT remained significant in multivariable analysis $(P<0.01, H R$ $5.84,95 \% \mathrm{Cl} 1.85-18.40$ ) (Table 2).

\section{Adverse Radiation Events}

ARE were observed in 12 patients (18\%) at a median of 4 months (IQR, 2-5 months). By the CTCAE classification, 6 patients ( $9 \%$ ) had grade 2 (increased seizure frequency, $n=4$; mild weakness, $n=1$; increased seizures and mild weakness, $n=1$ ), 5 patients $(7 \%)$ had grade 3 (new onset seizures, $n=2$; cyst formation causing apraxia and weakness, $n=1$; moderate weakness, $n=1$; moderate weakness and aphasia, $n=1)$, and 1 patient ( $1 \%$ ) had grade 4 (corneal ulcer requiring exenteration of the globe) complications. The 6-, 12 -, and 24 -month ARE rates were $16 \%, 16 \%$, and $18 \%$, respectively (Fig. 3A). Univariate analysis demonstrated patients with PIV $>10 \mathrm{~cm}^{3}$ more frequently had ARE $(P=0.02, \mathrm{HR} 4.94$, 95\% $\mathrm{Cl}$ 1.34-18.28) (Fig. 3B), with prior EBRT, and radiation dose approaching significance (Table 2). Multivariable analysis showed only prior EBRT was associated with an increased risk of ARE (P $=0.04$, HR 3.31, 95\% Cl 1.05-10.42). (Fig. 3C).

\section{Discussion}


In this study, we analyzed the outcomes of 68 patients having single-fraction SRS for AM over a 25-year period. Importantly, we excluded patients with radiation-induced and syndromic AM to better depict the results of SRS for patients most frequently encountered in clinical practice. Following SRS, in-field tumor control was high (84\%), but marginal and distant tumor progression was frequent (38\%), resulting in a 5year PFS of only $35 \%$. We did not find that higher radiation doses correlated with improved tumor control. This is nearly identical to the 5-year PFS after SRS for patients with AM in the multicenter study of Shepard et al (36\%),[19] and after EBRT in Radiation Therapy Oncology Group (RTOG) 0589 study (40\%). [14] However, the majority of recurrent tumors could be salvaged with repeat SRS, so that the 5-year DSS was $78 \%$. The most frequent ARE was new or increased seizures (CTCAE grades 2-3) which was managed successfully with anti-convulsant therapy in all cases. Overall, our results support the contention that SRS is a practical treatment option for patients with residual or recurrent AM, but theses tumors remain a management challenge and frequently require additional SRS, resection, or EBRT to prolong survival.

We found that prior EBRT was a negative predictor of tumor control, survival, and ARE. Specifically, the 5year PFS ( $0 \%$ versus $45 \%$ ) and DSS ( $53 \%$ versus $84 \%$ ) was worse for patients who had prior EBRT compared to those who did not have prior EBRT, and they had a greater risk of ARE (32\% versus $10 \%$ ). Prior studies generally support the concept that prior EBRT adversely affects outcomes after SRS of AM. [17-20] Zhang and colleagues reported 53 patients ( $A M, n=44 ; M M, n=9)$ undergoing CyberKnife SRS (median dose, $20 \mathrm{~Gy}$; median number of fractions, $\mathrm{n}=1$ ).[20] Twenty patients $(38 \%)$ had undergone prior EBRT. Multivariable analysis found tumor grade and prior radiation treatment were associated with a higher risk of tumor recurrence. Helis et al described 48 patients (183 tumors) having single-fraction SRS for AM and MM from 1999 until 2019.[17] Men and patients with MM had a greater risk of local or marginal tumor progression; they noted a trend $(P=0.08$ in multivariable analysis) toward increased risk in patients having prior EBRT. The retrospective, multicenter study conducted by International Radiosurgery Research Foundation included 271 patients ( $A M, n=233 ; M M, n=38$ ) having SRS; 55 patients (20\%) had prior EBRT.[19] Increasing age and a Ki-67 index $>15 \%$ negatively correlated with PFS. Prior EBRT was associated worse PFS $(P=0.01)$ and an increased risk of ARE $(P=0.04)$ in univariate analysis but was not a significant factor in multivariable analysis ( $P F S, P=0.06 ; A R E, P=0.1$ ). These findings suggest a resistance to ionized radiation in recurrent AM following EBRT,[22] yet SRS is frequently the best option for these patients despite outcomes that are inferior to radiation naïve patients.

The timing and type of radiation treatment in patients with AM is controversial. A number of studies advocate upfront adjuvant EBRT,[8-10] some reports favor post-operative surveillance with salvage radiotherapy especially for those following GTR, $[11-13,18]$ while a third group advocate for SRS either as an adjuvant or salvage technique.[15, 17, 19,20] We found that upfront adjuvant SRS and salvage SRS for late recurrences were equally effective, whereas salvage SRS for early recurrence (7-18 months following resection) was a significant risk for tumor progression. One explanation may be that patients with earlier disease progression have more aggressive tumors, perhaps related to increased proliferation indices, which has been correlated with reduced efficacy after SRS of AM and MM.[19] Furthermore, 
patients having adjuvant SRS may have smaller, less diffuse tumors that permit more optimal radiation targeting compared to patients having a STR who are observed until tumor growth is detected. Subset analyses of 14 radiation naïve patients having adjuvant SRS (median follow-up, 62 months) showed a 5year PFS of $54 \%$. Two patients underwent additional treatment (SRS $\times 3$, resection + EBRT); the 5- and 10year DSS was $88 \%$. Shepard et al found no difference in PFS based on indication (adjuvant versus salvage) for their entire study group compromising both $A M$ and $M M$, but a shortened interval between surgery and SRS correlated with improved PFS in patients with AM.[19] Zhang et al described a subset of AM patients with no history of prior radiation $(n=30)$ having SRS.[20] Tumor recurrence was noted in $2 / 12$ (17\%) patients having adjuvant SRS (0-4 months after resection) compared to 8/18 (44\%) patients SRS in a more delayed fashion, but this was not statistically significant $(P=0.11)$. Overall, the importance of timing of SRS and prognosis is poorly understood. Analyzing the time from resection to SRS as a continuous or dichotomized binary variable may hide its true effect. Our results showing either adjuvant ( $\leq 6$ months) or late salvage SRS ( $>18$ months) was superior to early salvage SRS (7-18 months) need further research to ensure its validity.

This study is subject to the limitations of all retrospective, single-center patient series including limited patient number, selection bias, and incomplete follow-up. Yet, apart from the prospective trial RTOG 0539, [14] other comparable studies on the management of AM have the similar problems but also include both $\mathrm{AM}$ and $\mathrm{MM}$. The major weakness of this study is that we were unable to analyze the effect of histopathological factors and labeling indices in our analysis due to lack of consistent data. However, by focusing on a cohort consisting of only $\mathrm{AM}$ and excluding patients with radiation-induced and syndromic tumors, our study provides meaningful information on the results of SRS for the type of patient most frequently encountered in clinical practice.

\section{Conclusions}

Single-fraction SRS provides a high rate of in-field tumor control for patients with residual or recurrent AM, but tumor progression outside the treated volume is common and additional procedures are often necessary. Prior EBRT was the primary factor associated with decreased PFS, decreased DSS, and an increased risk of ARE. Patients having SRS as a post-operative adjunct or later tumor progression appear to have better PFS, but further study is needed to determine the optimal timing of SRS for patients with AM.

\section{Declarations}

\section{Acknowledgments}

None.

Funding: None.

Conflicts of interest/Competing interests: The authors have nothing to declare. 
Availability of data and material: The data used in the present study will be available upon reasonable request to the corresponding author.

Code availability: Not applicable.

Ethics approval: The study was approved by Institutional Review board (IRB \#21-000215).

Consent to participate: Informed consent was waived given the retrospective non-invasive nature of the study.

\section{Authors' contributions:}

Hirotaka Hasegawa: conceptualization, data acquisition, analysis, interpretation, drafting manuscript, final approval of the version to be published

Kunal Vakharia: data acquisition, final approval of the version to be published

Michael J. Link: critically revising manuscript, final approval of the version to be published

Scott L. Stafford: critically revising manuscript, final approval of the version to be published

Paul D. Brown: critically revising manuscript, final approval of the version to be published Ian F. Parney: critically revising manuscript, final approval of the version to be published

Terry C. Burns: critically revising manuscript, final approval of the version to be published Elizabeth S Yan: critically revising manuscript, final approval of the version to be published Anita Mahajan: critically revising manuscript, final approval of the version to be published Nadia N. Laack: critically revising manuscript, final approval of the version to be published Bruce E. Pollock: conceptualization, data analysis, interpretation, critically revising manuscript, final approval of the version to be published

\section{References}

1. Porter KR, McCarthy BJ, Freels S, Kim Y, Davis FG (2010) Prevalence estimates for primary brain tumors in the United States by age, gender, behavior, and histology. Neuro Oncol 12: 520-527 doi:10.1093/neuonc/nop066

2. Kleihues P, Cavenee WK, International Agency for Research on Cancer. (2000) Pathology and genetics of tumours of the nervous system. IARC Press, Lyon 
3. World Health Organization., International Agency for Research on Cancer. (2007) WHO classification of tumours of the central nervous system. International Agency for Research on Cancer, Lyon

4. Louis DN, Ohgaki H, Wiestler OD, Cavenee WK, World Health Organization, International Agency for Research on Cancer (2016) WHO classification of tumours of the central nervous system. International Agency For Research On Cancer, Lyon

5. Kshettry VR, Ostrom QT, Kruchko C, Al-Mefty O, Barnett GH, Barnholtz-Sloan JS (2015) Descriptive epidemiology of World Health Organization grades II and III intracranial meningiomas in the United States. Neuro Oncol 17: 1166-1173 doi:10.1093/neuonc/nov069

6. Rogers L, Gilbert M, Vogelbaum MA (2010) Intracranial meningiomas of atypical (WHO grade II) histology. J Neurooncol 99: 393-405 doi:10.1007/s11060-010-0343-1

7. Sun SQ, Hawasli AH, Huang J, Chicoine MR, Kim AH (2015) An evidence-based treatment algorithm for the management of WHO Grade II and III meningiomas. Neurosurg Focus 38: E3 doi:10.3171/2015.1.FOCUS14757

8. Aghi MK, Carter BS, Cosgrove GR, Ojemann RG, Amin-Hanjani S, Martuza RL, Curry WT, Jr., Barker FG, 2nd (2009) Long-term recurrence rates of atypical meningiomas after gross total resection with or without postoperative adjuvant radiation. Neurosurgery 64: 56-60; discussion 60 doi:10.1227/01.NEU.0000330399.55586.63

9. Bagshaw HP, Burt LM, Jensen RL, Suneja G, Palmer CA, Couldwell WT, Shrieve DC (2017) Adjuvant radiotherapy for atypical meningiomas. J Neurosurg 126: 1822-1828 doi:10.3171/2016.5.JNS152809

10. Bray DP, Quillin JW, Press RH, Yang Y, Chen Z, Eaton BR, Olson JJ (2021) Adjuvant Radiotherapy Versus Watchful Waiting for World Health Organization Grade II Atypical Meningioma: A Single-Institution Experience. Neurosurgery 88: E435-E442 doi:10.1093/neuros/nyaa580

11. Graffeo CS, Leeper HE, Perry A, Uhm JH, Lachance DJ, Brown PD, Ma DJ, Van Gompel JJ, Giannini C, Johnson DR, Raghunathan A (2017) Revisiting Adjuvant Radiotherapy After Gross Total Resection of World Health Organization Grade II Meningioma. World Neurosurg 103: 655-663 doi:10.1016/j.wneu.2017.04.095

12. Hasan S, Young M, Albert T, Shah AH, Okoye C, Bregy A, Lo SS, Ishkanian F, Komotar RJ (2015) The role of adjuvant radiotherapy after gross total resection of atypical meningiomas. World Neurosurg 83: 808-815 doi:10.1016/j.wneu.2014.12.037

13. Pereira BJA, de Almeida AN, Paiva WS, Teixeira MJ, Marie SKN (2019) Impact of radiotherapy in atypical meningioma recurrence: literature review. Neurosurg Rev 42: 631-637 doi:10.1007/s10143-018- 
14. Rogers CL, Won M, Vogelbaum MA, Perry A, Ashby LS, Modi JM, Alleman AM, Galvin J, Fogh SE, Youssef E, Deb N, Kwok Y, Robinson CG, Shu HK, Fisher BJ, Panet-Raymond V, McMillan WG, de Groot JF, Zhang P, Mehta MP (2020) High-risk Meningioma: Initial Outcomes From NRG Oncology/RTOG 0539. Int J Radiat Oncol Biol Phys 106: 790-799 doi:10.1016/j.jirobp.2019.11.028

15. Aboukais R, Zairi F, Lejeune JP, Le Rhun E, Vermandel M, Blond S, Devos P, Reyns N (2015) Grade 2 meningioma and radiosurgery. J Neurosurg 122: 1157-1162 doi:10.3171/2014.9.JNS14233

16. Hardesty DA, Wolf AB, Brachman DG, McBride HL, Youssef E, Nakaji P, Porter RW, Smith KA, Spetzler RF, Sanai N (2013) The impact of adjuvant stereotactic radiosurgery on atypical meningioma recurrence following aggressive microsurgical resection. J Neurosurg 119: 475-481 doi:10.3171/2012.12.JNS12414

17. Helis CA, Hughes RT, Cramer CK, Tatter SB, Laxton AW, Bourland JD, Munley MT, Chan MD (2020) Stereotactic Radiosurgery for Atypical and Anaplastic Meningiomas. World Neurosurg 144: e53-e61 doi:10.1016/j.wneu.2020.07.211

18. Pollock BE, Stafford SL, Link MJ, Garces Yl, Foote RL (2012) Stereotactic radiosurgery of World Health Organization grade II and III intracranial meningiomas: treatment results on the basis of a 22-year experience. Cancer 118: 1048-1054 doi:10.1002/cncr.26362

19. Shepard MJ, Xu Z, Kearns K, Li C, Chatrath A, Sheehan K, Sheehan D, Faramand A, Niranjan A, Kano H, Gurewitz J, Bernstein K, Liscak R, Guseynova K, Grills IS, Parzen JS, Cifarelli CP, Rehman AA, Atik A, Bakhsheshian J, Zada G, Chang E, Giannotta S, Speckter H, Wu HM, Kondziolka D, Golfinos JG, Mathieu D, Lee CC, Warnick RE, Lunsford LD, Sheehan JP (2021) Stereotactic Radiosurgery for Atypical (World Health Organization II) and Anaplastic (World Health Organization III) Meningiomas: Results From a Multicenter, International Cohort Study. Neurosurgery doi:10.1093/neuros/nyaa553

20. Zhang M, Ho AL, D'Astous M, Pendharkar AV, Choi CY, Thompson PA, Tayag AT, Soltys SG, Gibbs IC, Chang SD (2016) CyberKnife Stereotactic Radiosurgery for Atypical and Malignant Meningiomas. World Neurosurg 91: 574-581 e571 doi:10.1016/j.wneu.2016.04.019

21. Bland JM, Altman DG (1995) Multiple significance tests: the Bonferroni method. BMJ 310: 170 doi:10.1136/bmj.310.6973.170

22. Barker HE, Paget JT, Khan AA, Harrington KJ (2015) The tumour microenvironment after radiotherapy: mechanisms of resistance and recurrence. Nat Rev Cancer 15: 409-425 doi:10.1038/nrc3958

\section{Tables}


Table 1 Patient and Tumor Characteristics of 68 Patients Having Single-fraction SRS for Atypical (WHO II) Meningiomas 


\begin{tabular}{|ll|}
\hline Characteristic & Value \\
\hline Female & $36(53 \%)$ \\
\hline Patient age at SRS, years & $66(53-74)$ \\
\hline Tumor location & \\
Convexity/parasagittal & $56(82 \%)$ \\
Skull base/tentorium & $12(18 \%)$ \\
\hline Symptoms at SRS & \\
Asymptomatic & $38(56 \%)$ \\
Hemi-paresis & $13(19 \%)$ \\
Seizures & $13(19 \%)$ \\
Cranial nerve deficit & $10(15 \%)$ \\
Aphasia & $5(7 \%)$ \\
Visual deficits & $2(3 \%)$ \\
Sensory disturbance & $1(1 \%)$ \\
Cognitive decline & $1(1 \%)$ \\
\hline No. of resections & $1(1-2)$ \\
\hline Time from last resection & $17(25 \%)$ \\
Continuous value (months) & $18(6-45)$ \\
\hline Upfront adjuvant ( 6 months) & $18(26 \%)$ \\
Early salvage (7-18 months) & $17(25 \%)$ \\
Late salvage (> 18 months) & $33(49 \%)$ \\
\hline Extent of resection at last surgery & \\
GTR & $39(57 \%)$ \\
STR & $29(43 \%)$ \\
\hline Prior EBRT & $19(28 \%)$ \\
\hline Tume from EBRT, months & \\
\hline Mingle tumor & \\
\hline
\end{tabular}


Abbreviations: EBRT = external beam radiation therapy; GTR = gross total resection; $\mathrm{SRS}=$ stereotactic radiosurgery; STR = subtotal resection; $\mathrm{WHO}=$ World Health Organization .

Data presented as median (interquartile range) or $\mathrm{n}(\%)$.

Some patients displayed multiple symptoms prior to SRS.

GTR defined as a Simpson grade I-II resection.

For patients with multi-focal tumors, the tumor diameter recorded is for the largest tumor.

Table 2 Analyses of Factors Associated with PFS, DSS, and ARE 


\begin{tabular}{|c|c|c|c|c|c|c|c|}
\hline \multirow{2}{*}{\multicolumn{2}{|c|}{ Factor }} & \multicolumn{3}{|c|}{$\begin{array}{l}\text { Univariate Analysis } \\
\mathrm{HR}, 95 \% \mathrm{Cl} \\
\text { (P value) }\end{array}$} & \multicolumn{3}{|c|}{$\begin{array}{l}\text { Multivariable Analysis } \\
\mathrm{HR}, 95 \% \mathrm{Cl} \\
\text { (P value) }\end{array}$} \\
\hline & & PFS & DSS & ARE & PFS & DSS & ARE \\
\hline \multirow{2}{*}{\multicolumn{2}{|c|}{$\begin{array}{l}\text { Male sex } \\
\text { (vs. female) }\end{array}$}} & $\begin{array}{l}1.24 \\
0.64- \\
2.40\end{array}$ & $\begin{array}{l}0.62 \\
0.23- \\
1.68\end{array}$ & $\begin{array}{l}2.30 \\
0.69- \\
7.63\end{array}$ & - & - & - \\
\hline & & $(0.52)$ & $(0.35)$ & $(0.16)$ & & & \\
\hline \multirow{2}{*}{\multicolumn{2}{|c|}{$\begin{array}{l}\text { Age } \\
\text { (continuous, years) }\end{array}$}} & $\begin{array}{l}1.01 \\
0.99- \\
1.04\end{array}$ & $\begin{array}{l}1.00 \\
0.97- \\
1.04\end{array}$ & $\begin{array}{l}1.02 \\
0.98- \\
1.07\end{array}$ & - & - & - \\
\hline & & $(0.32)$ & $(0.83)$ & $(0.37)$ & & & \\
\hline \multirow{2}{*}{\multicolumn{2}{|c|}{$\begin{array}{l}\text { Convexity/falx } \\
\text { location } \\
\text { (vs. skull } \\
\text { base/tentorial) }\end{array}$}} & $\begin{array}{l}1.95 \\
0.75- \\
5.09\end{array}$ & $\begin{array}{l}0.86 \\
0.27- \\
2.69\end{array}$ & $\begin{array}{l}2.57 \\
0.33- \\
19.88\end{array}$ & - & - & - \\
\hline & & $(0.17)$ & $(0.79)$ & $(0.37)$ & & & \\
\hline \multirow[t]{7}{*}{$\begin{array}{l}\text { Timing } \\
\text { of SRS }\end{array}$} & $\begin{array}{l}\text { P value } \\
\text { (entire } \\
\text { model) }\end{array}$ & $<0.01$ & 0.10 & 0.73 & $<0.01$ & - & - \\
\hline & $\begin{array}{l}\text { E-Slvg (vs. } \\
\text { Adjv) }\end{array}$ & $\begin{array}{l}2.98 \\
1.23- \\
7.21\end{array}$ & $\begin{array}{l}2.39 \\
0.69- \\
8.22\end{array}$ & $\begin{array}{l}1.51 \\
0.34- \\
6.77\end{array}$ & \multirow{2}{*}{$\begin{array}{l}3.17,1.29- \\
7.80 \\
(0.01)^{*}\end{array}$} & \multirow[t]{2}{*}{-} & \multirow[t]{2}{*}{-} \\
\hline & & $(0.015)^{\star}$ & $(0.17)^{\star}$ & $(0.69)^{*}$ & & & \\
\hline & $\begin{array}{l}\text { E-Slvg (vs. } \\
\text { L-Slvg) }\end{array}$ & $\begin{array}{l}3.17 \\
1.49- \\
6.79\end{array}$ & $\begin{array}{l}3.35 \\
1.06- \\
10.64\end{array}$ & $\begin{array}{l}1.67 \\
0.45- \\
6.22\end{array}$ & \multirow{2}{*}{$\begin{array}{l}4.39,1.97- \\
9.78 \\
(<0.01) \star\end{array}$} & \multirow[t]{2}{*}{-} & \multirow[t]{2}{*}{-} \\
\hline & & $(<0.01)^{*}$ & $(0.04)^{\star}$ & $(0.44)^{*}$ & & & \\
\hline & \multirow[t]{2}{*}{$\begin{array}{l}\text { Adjv (vs. L- } \\
\text { Slvg) }\end{array}$} & $\begin{array}{l}1.30 \\
0.54- \\
3.15\end{array}$ & $\begin{array}{l}1.40 \\
0.38- \\
5.24\end{array}$ & $\begin{array}{l}1.10 \\
0.26- \\
4.62\end{array}$ & \multirow{2}{*}{$\begin{array}{l}1.38,0.57- \\
3.37 \\
(0.47)^{\star}\end{array}$} & \multirow[t]{2}{*}{-} & \multirow[t]{2}{*}{-} \\
\hline & & $(0.56)^{\star}$ & $(0.61)^{\star}$ & $(0.89) *$ & & & \\
\hline \multirow{2}{*}{\multicolumn{2}{|c|}{$\begin{array}{l}\text { STR at last resection } \\
\text { (vs. GTR) }\end{array}$}} & $\begin{array}{l}0.96 \\
0.50- \\
1.87\end{array}$ & $\begin{array}{l}2.52 \\
0.87- \\
7.27\end{array}$ & $\begin{array}{l}0.95 \\
0.30- \\
3.00\end{array}$ & - & $\begin{array}{l}2.74 \\
0.95- \\
7.99\end{array}$ & - \\
\hline & & $(0.92)$ & $(0.09)$ & $(0.93)$ & & $(0.06)$ & \\
\hline \multirow{2}{*}{\multicolumn{2}{|c|}{$\begin{array}{l}\text { Multiple tumors } \\
\text { (vs. single tumor) }\end{array}$}} & $\begin{array}{l}1.61 \\
0.79- \\
3.28\end{array}$ & $\begin{array}{l}2.65 \\
1.02- \\
7.15\end{array}$ & $\begin{array}{l}1.74 \\
0.52- \\
5.77\end{array}$ & \multirow[t]{2}{*}{ - } & $\begin{array}{l}1.47 \\
0.51- \\
4.26\end{array}$ & \multirow[t]{2}{*}{-} \\
\hline & & $(0.19)$ & $(0.04)$ & $(0.37)$ & & $(0.48)$ & \\
\hline
\end{tabular}




\begin{tabular}{|c|c|c|c|c|c|c|}
\hline $\begin{array}{l}\text { Prior EBRT } \\
\text { (vs. no prior EBRT) }\end{array}$ & $\begin{array}{l}4.47 \\
2.16- \\
9.25 \\
(<0.01)\end{array}$ & $\begin{array}{l}6.15 \\
2.09- \\
18.07 \\
(<0.01)\end{array}$ & $\begin{array}{l}3.00 \\
0.97- \\
9.33 \\
(0.06)\end{array}$ & $\begin{array}{l}5.92,2.67- \\
13.04 \\
(<0.01)\end{array}$ & $\begin{array}{l}5.84 \\
1.85- \\
18.40 \\
(<0.01)\end{array}$ & $\begin{array}{l}3.31,1.05- \\
10.42 \\
(0.04)\end{array}$ \\
\hline $\begin{array}{l}\text { PIV > } 10 \mathrm{~cm}^{3} \\
\left.\text { (vs. } \leq 10 \mathrm{~cm}^{3}\right)\end{array}$ & $\begin{array}{l}0.91 \\
0.47- \\
1.78 \\
(0.79)\end{array}$ & $\begin{array}{l}1.56 \\
0.60- \\
4.09 \\
(0.37)\end{array}$ & $\begin{array}{l}4.94 \\
1.34- \\
18.28 \\
(0.02)\end{array}$ & - & - & $\begin{array}{l}3.42,0.80- \\
14.57 \\
(0.10)\end{array}$ \\
\hline $\begin{array}{l}\text { Margin dose } \leq 16 \mathrm{~Gy} \\
\text { (vs. > } 16 \mathrm{~Gy})\end{array}$ & $\begin{array}{l}0.96 \\
0.49- \\
1.88 \\
(0.90)\end{array}$ & $\begin{array}{l}1.20 \\
0.43- \\
3.30 \\
(0.73)\end{array}$ & $\begin{array}{l}7.71 \\
1.00- \\
59.79 \\
(0.05)\end{array}$ & - & - & $\begin{array}{l}3.54,0.37- \\
33.87 \\
(0.27)\end{array}$ \\
\hline $\begin{array}{l}\text { Margin dose } \leq 18 \mathrm{~Gy} \\
\text { (vs. > } 18 \mathrm{~Gy} \text { ) }\end{array}$ & $\begin{array}{l}0.69 \\
0.28- \\
1.69 \\
(0.42)\end{array}$ & $\begin{array}{l}3.22 \\
0.28- \\
1.69 \\
(0.26)\end{array}$ & $\begin{array}{l}6.41 \times 10^{8} \\
N^{\star \star} \\
0.99\end{array}$ & - & - & - \\
\hline $\begin{array}{l}\text { Maximum dose } \leq 32 \\
\text { Gy } \\
\text { (vs. > } 32 \text { Gy) }\end{array}$ & $\begin{array}{l}0.75 \\
0.39- \\
1.46 \\
(0.40)\end{array}$ & $\begin{array}{l}0.62 \\
0.23- \\
1.66 \\
(0.34)\end{array}$ & $\begin{array}{l}4.35 \\
0.95- \\
19.85 \\
\\
(0.06)\end{array}$ & - & - & - \\
\hline
\end{tabular}

* Bonferroni's corrected cutoff P-value (0.017) was used . $\quad$ ** $95 \% \mathrm{Cl}$ could not be calculated.

Abbreviations: Adjv = upfront adjuvant; $\mathrm{ARE}$ = adverse radiation effect; $\mathrm{Cl}=$ confidence interval; $\mathrm{DSS}=$ disease specific survival; EBRT = external beam radiation therapy; E-Slvg = early salvage; GTR = gross total resection; HR = hazard ratio; $L C=$ local control; L-Slvg = late salvage; NA = not applicable; PFS = progression-free survival; PIV = prescription isodose volume; $S R S$ = stereotactic radiosurgery; STR = subtotal resection

Figures

A

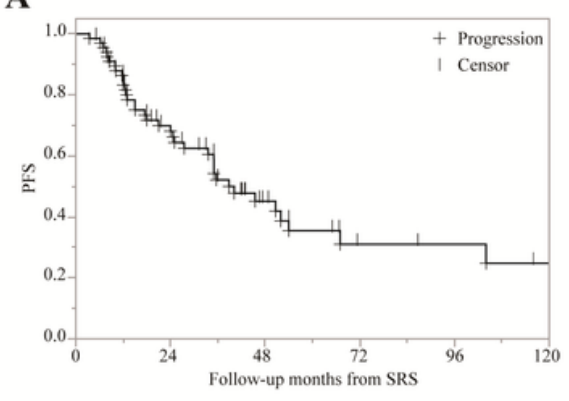

Number at risk

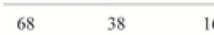

B

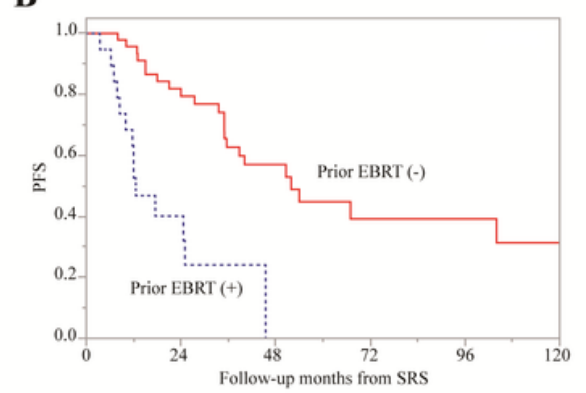

Number at risk

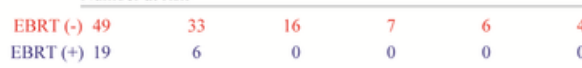

C

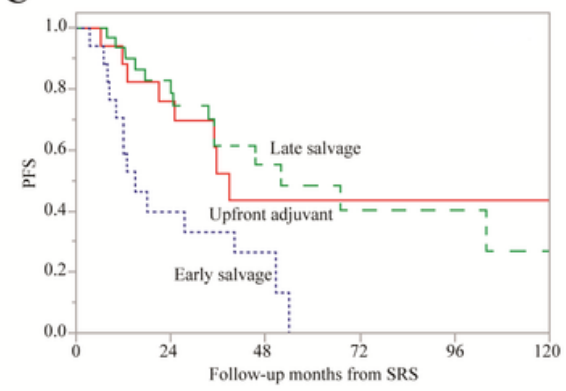

Number at risk

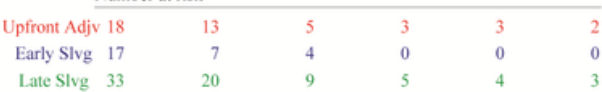


Figure 1

Kaplan-Meier curves for progression-free survival (PFS). (A) The entire cohort. (B) Stratification by a history of prior external beam radiotherapy (EBRT). (C) Stratification according to the timing of radiosurgery. Adjv = adjuvant; Slvg = salvage; $\mathrm{SRS}$ = stereotactic radiosurgery

A

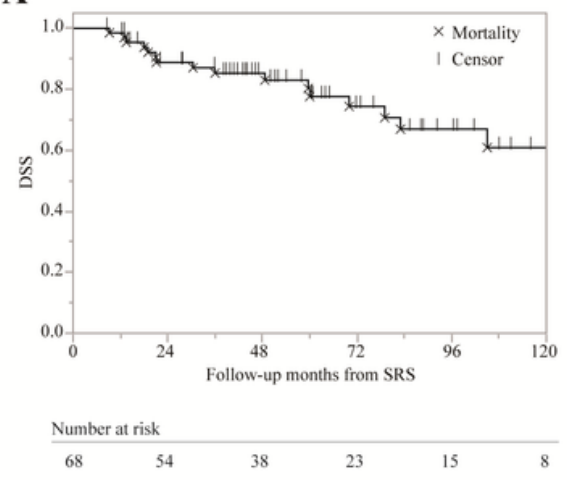

B
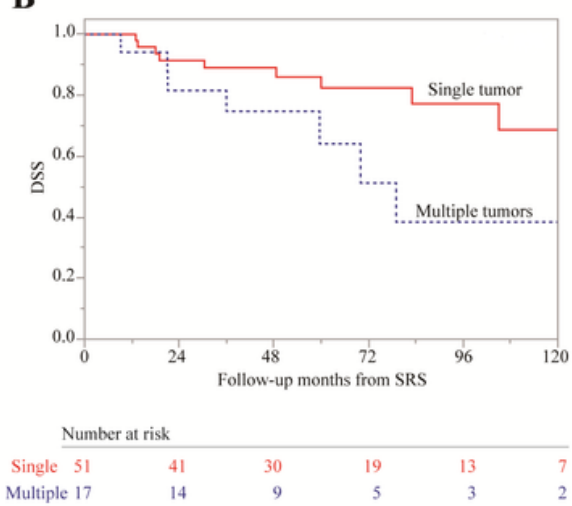

C

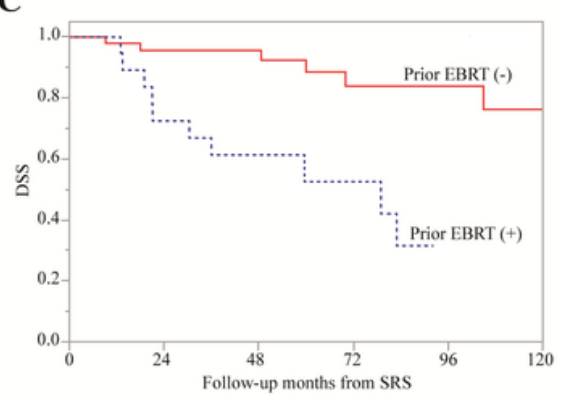

Prior EBRT (-) 49 Prior EBRT $(+) 19$

\section{Figure 2}

Kaplan-Meier curves for disease-specific survival (DSS). (A) The entire cohort. (B) Stratification by tumor morphology. (C) Stratification by a history of prior external beam radiotherapy (EBRT). SRS = stereotactic radiosurgery

A

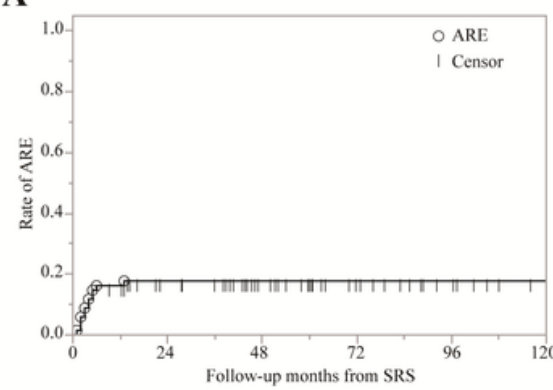

Number at risk
68
B

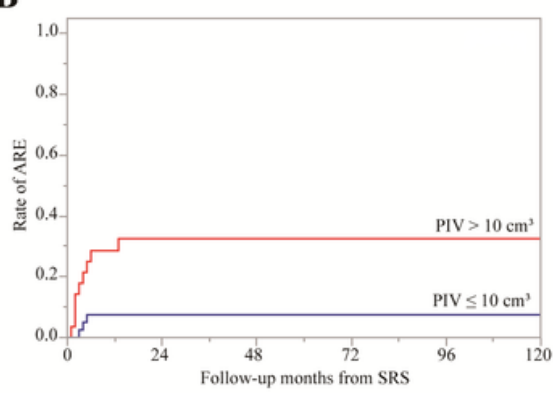

Number at risk $\begin{array}{lrrrrr}\text { PIV }>10 \mathrm{~cm}^{3} 28 & 15 & 9 & 5 & 4 & 3 \\ \text { PIV } \leq 10 \mathrm{~cm}^{3} 40 & 33 & 24 & 17 & 10 & 5\end{array}$
C

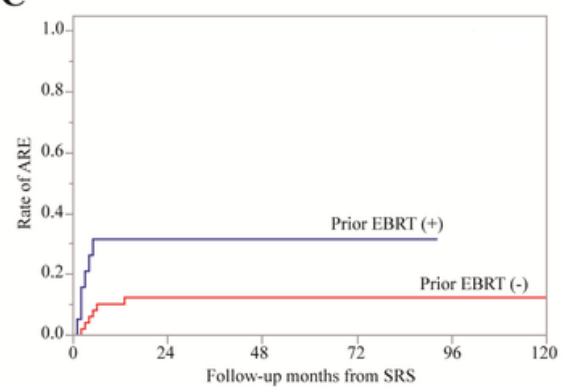

Number at risk

Prior EBRT $(+) 19$

\section{Figure 3}

Kaplan-Meier curves for adverse radiation event (ARE). (A) The entire cohort. (B) Stratification by planned isodose volume (PIV). (C) Stratification by a history of prior external beam radiotherapy (EBRT). SRS = stereotactic radiosurgery 